\title{
An endophytic isolate of the fungus Yarrowia lipolytica produces metabolites that ameliorate the negative impact of salt stress on the physiology of maize
}

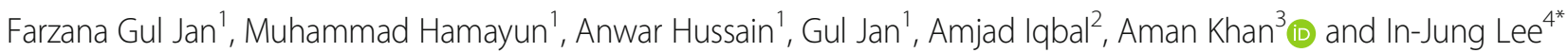

\begin{abstract}
Background: To combat salinity, plants need easily accessible, safe and sustainable mechanisms for optimum growth. Recently, endophytes proved to be the promising candidates that helped the host plant to thrive under stress conditions. Therefore, the aim was to discover endophytic strain(s) and their mechanism of action to alleviate salt stress in maize.

Results: Keeping the diverse role of endophytes in view, 9 endophytic fungi from the spines of Euphorbia milli L. were isolated. Among the isolated fungal isolates, isolate $\mathrm{FH} 1$ was selected for further study on the basis of high antioxidant activity and capability to produce high indole-3-acetic acid (IAA), indole-3-acetamide (IAM), phenol and flavonoid contents. The 18S rDNA sequence homology and phylogenetic analysis of the fungal isolate FH1 revealed to be Yarrowia lipolytica. Furthermore, the inoculation of Y. lipolytica $\mathrm{FH} 1$ had significantly promoted plant growth attributes in treated maize as compared to positive (salt stress) and negative (salt stress free) controls. Likewise, differences in chlorophyll, carotenes, electrolyte leakage, leaf relative water, peroxidase, catalase, ABA, IAA and proline contents were observed between treated maize and controls. Interestingly, Y. lipolytica FH1 inoculated plants showed lower endogenous ABA and higher endogenous IAA contents.

Conclusion: From the results, we have concluded that $Y$. lipolytica inoculation has promoted the growth of maize plants through controlled metabolism and hormonal secretions (ABA and IAA) under salinity stress. Because of the fact, Y. lipolytica can be tried as an eco-friendly bio-fertilizer to achieve optimum crop productivity under saline conditions.
\end{abstract}

Keywords: Y. lipolytica FH1, Salt stress, Indole-3-acetic acid, Abscisic acid, Phenols, Flavonoids, Maize

\section{Background}

Maize (Zea mays L.) is an important cereal that contributes towards human food and animal feed worldwide [1]. The major maize producing countries include USA, Mexico, Nigeria, France, and Hungary. In Pakistan, maize is grown for the fresh market in various parts of Khyber Pakhtunkhwa. But the productivity of this valuable crop has been decreased over the years due to continuous change in the environment. Amongst various factors,

\footnotetext{
* Correspondence: ijlee@knu.ac.kr

${ }^{4}$ School of Applied Biosciences, College of Agriculture and Life Sciences, Kyungpook National University, Daegu, South Korea

Full list of author information is available at the end of the article
}

salinity is one of the reasons that drastically affected the maize growth and productivity [2]. Salinity is in fact a global issue because more than 70 countries of the worlds have been marked by this problem. Also, rapid increases in the area of salt-affected land (45 million hectares in 1992 to 62 million ha in 2013) indicate the devastating nature of the problem. Based on this data, it is extrapolated that an area of 2000 ha catches salinity every day [3]. According to the statistical calculations, almost 6.5 million hectares of irrigated land in Pakistan is severely affected by various levels of salinity [4].

Interestingly, the most common source of salinity is irrigation water itself. Significant quantities of salts are

(c) The Author(s). 2019 Open Access This article is distributed under the terms of the Creative Commons Attribution 4.0 International License (http://creativecommons.org/licenses/by/4.0/), which permits unrestricted use, distribution, and 
contributed by using fresh water in irrigation, which was believed to have a negligible amount of salts. In dry hot areas, accumulation of salts is faster because of the rapid evaporation of irrigated water [3]. Climate change and high evaporation rate enhances salt accumulation in soil, which reduces soil water potential and water uptake by plant roots [5]. Prolonged exposures of plants to salinity results in excess accumulation of $\mathrm{Na}^{+}$into plants, thus disturbing $\mathrm{K}^{+} / \mathrm{Na}^{+}$balance and ultimately plant metabolism. Besides, plants exposed to salt stress can produce/accumulate excessive amounts of reactive oxygen species (ROS), disturbing electron transport chain in chloroplast and mitochondria [6]. Other consequences of hyper-accumulation of ROS, include membrane damage, cellular proteins, chlorophyll and nucleic acids damages [7].

To control production losses related to salinity in economically important crops, concrete biological measures are needed to optimize crop yield. Endophytic fungi residing in plant tissues can serve the purpose at the best [8]. Currently, utilization of endophytic fungi to mitigate severe salt stress in an environmental friendly way is an emerging technique to fix the problem. Endophytes can regulate plant physiological activities against abiotic stresses by releasing and/or enhancing the capability of the host plant to produce phytohormones (gibberellins, auxin, cytokinin, abscisic acid) and secondary metabolites (phenols and flavonoids) [9]. IAA is known to control root growth under salinity stress, inhibit $\mathrm{H}_{2} \mathrm{O}_{2}$ production, antagonize ethylene-based abscission and promote overall plant growth [10]. Flavonoids, on the other hand, can trigger IAA accumulation in the root nodules of host plants and motivate colonization of endophytes under stress conditions [8]. Similarly, ABA can control stomatal functioning to minimize water losses. Also, it can regulate stress-responsive genes to mediate plant defense system against stress damages [11]. Though there are studies related to the plant-microbe interaction, yet the field is still open to discover endophytes and their interactions with host plants under stress. In this study, we have focused on the role of endophytic $Y$. lipolytica $\mathrm{FH} 1$ in alleviating salt stress in maize seedlings.

\section{Results}

Isolation of FH1 from the spines of Euphorbia milli

From the surface sterilized spines of Euphorbia milli about 9 endophytic fungal strains were isolated. Furthermore, only the FH1 isolate have shown resistance to $100 \mathrm{mM}$ $\mathrm{NaCl}$ salt stress and selected for further study.

\section{Physicochemical characteristics of $\mathrm{FH} 1$ strain}

A $90 \%$ of fungal colonization frequency was observed on spine segments placed in Hagem media plates with FH1 (38\%) was the most dominant colonizer (Table 1). Similarly, the isolate FH1 produced IAA, polyphenols and flavonoids in appreciable quantities and exhibited DPPH activity (Table 1).

\section{Molecular identification and phylogenetic analysis of $\mathrm{FH} 1$}

The isolate FH1 was identified by comparing its internal transcribed spacer (ITS) region including a partial sequence of $18 \mathrm{~S}$ rDNA, the complete sequence of ITS1 and ITS2, the complete sequence of 5.8S rDNA and partial sequence of $28 \mathrm{~S}$ rDNA genes sequence with the related sequences available in the GenBank database of NCBI (https://blast.ncbi.nlm.nih.gov/Blast.cgi). The isolate $\mathrm{FH} 1$ sequence showed 99\% homology, 99\% query coverage and 0.0 E values with $99 \%$ identity to Yarrowia lipolytica. The closely related sequences were retrieved from GenBank and subjected to phylogenetic analysis by using MEGA 7 to construct maximum likelihood tree. The isolate was grouped with Yarrowia lipolytica having 99 bootstrap supports (Fig. 1). The gene sequence of the isolate FH1 was submitted to NCBI GenBank and was allotted with accession no. KY673731.

\section{Physicochemical alterations in Y. lipolytica inoculated maize plants under salt stress \\ Effect on chlorophyll and carotenoid contents of maize plants}

The fungal isolate FH1 greatly promoted the growth attributes of maize plants under salt stress, as the $Y$. lipolytica FH1 inoculated plants showed higher plant growth and pigmentation under stress conditions (Fig. 2). The fungal associated maize seedlings under salinity possessed significantly $(P<0.05)$ higher chlorophyll a (Fig. 2a), chlorophyll b (Fig. 2b) and carotenoid (Fig. 2c) contents compared to their respective controls.

\section{Effect on growth parameters, electrolyte leakage, and relative water contents}

From the results it is quite evident that the selected salts have significantly $(P<0.05)$ reduced plant weight as compared to the control (Fig. 3a). On the other hand,

Table 1 Potential of FH1 to colonize E. milli spine, exhibit DPHH activity and production of IAA, polyphenols and flavonoids

\begin{tabular}{llcccc}
\hline Fungal isolate & Colonization (\%) & DPPH activity (\%) & IAA $(\mu \mathrm{g} / \mathrm{ml})$ & Phenolics $(\mu \mathrm{g} / \mathrm{ml})$ & Flavonoids $(\mu \mathrm{g} / \mathrm{ml})$ \\
\hline FH1 & 38 of 90 & $65 \pm 8.52$ & $9.17 \pm 0.92$ & $65.5 \pm 3.95$ & $10.6 \pm 0.61$ \\
\hline
\end{tabular}

Colonization was measured as colonization frequency by plating spine segments on Hagem media plates at $28^{\circ} \mathrm{C}$ for 7 days and counted the number of segments with endophytic colonies. About $90 \%$ of the segments were colonized by the 9 strains of endophytes, whereas $38 \%$ was colonized by $\mathrm{FH} 1$ 


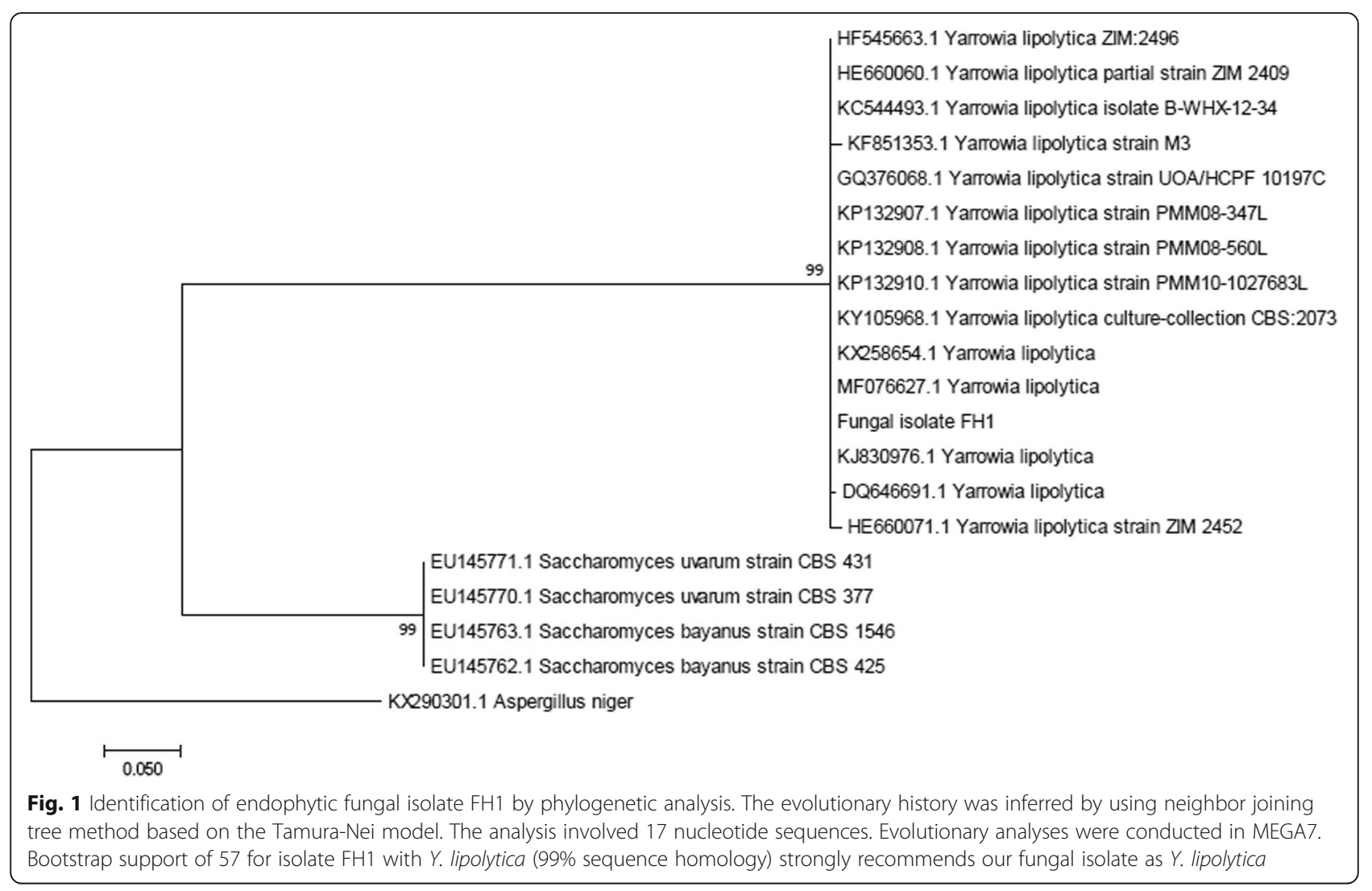

the salt stressed maize plants inoculated with $Y$. lipolytica FH1had lost less weight as compared to the control. A significantly $(P<0.05)$ higher weight have attained by the non-stressed, FH1 inoculated maize plants (Fig. 3a). Similarly, maize seedlings in association with FH1 have significantly longer roots and shoots as compared to the non-associated maize plants with or without salt stress (Fig. 3b).

Moreover, the electrolyte leakage was found significantly $(\mathrm{P}<0.05)$ higher in salt stress treatments as compared to control (Fig. 3c). The $\mathrm{NaCl}(100 \mathrm{mM})$ triggered electrolytes leakage by 2.5 times higher, while the effect of $\mathrm{KCl}$ and $\mathrm{K}_{2} \mathrm{SO}_{4}$ (100 mM each) was 2 times as compared to the control. However, the fungal association has reduced the electrolyte leakage in maize seedlings under saline conditions (Fig. 3c). Likewise, a significant decrease in relative water content (RWC) of maize seedlings was observed in salt-stressed treatments (Fig. 3d). The RWC was higher in maize plants associated with $Y$. lipolytica FH1. A non-significant $(P<0.05)$

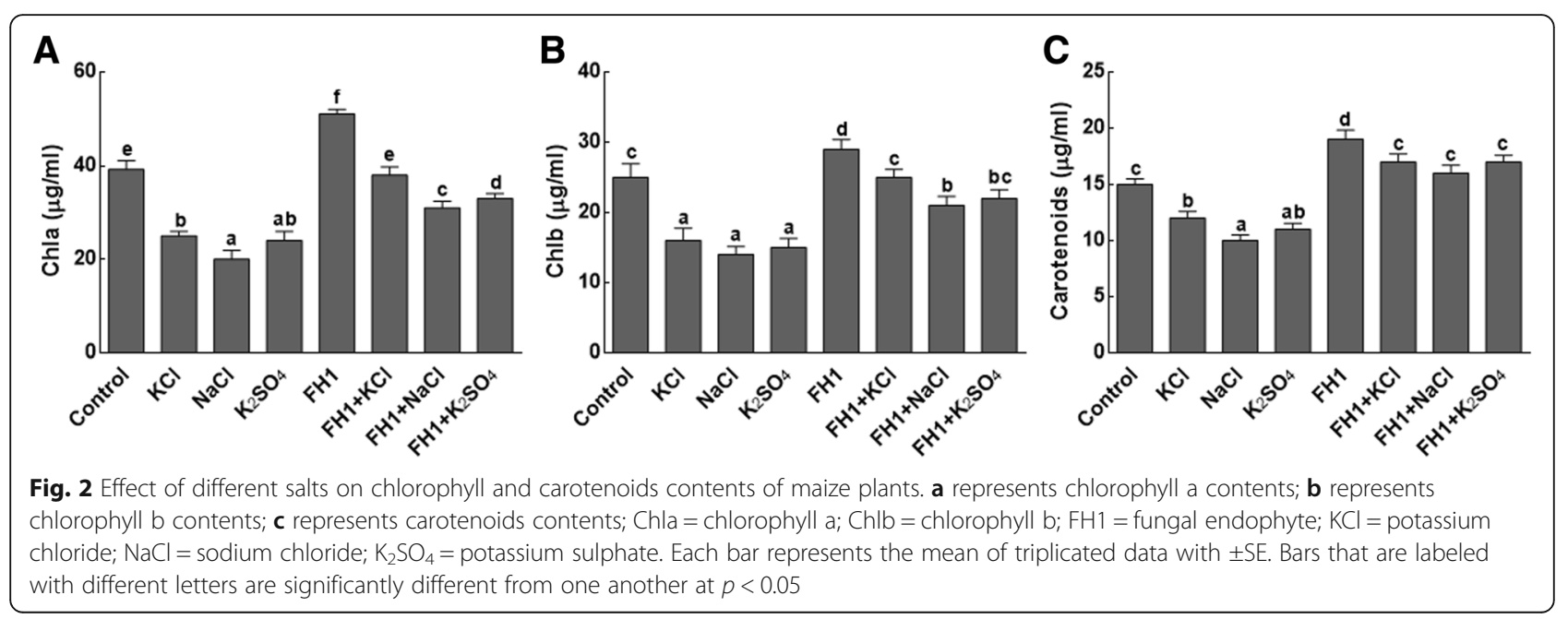



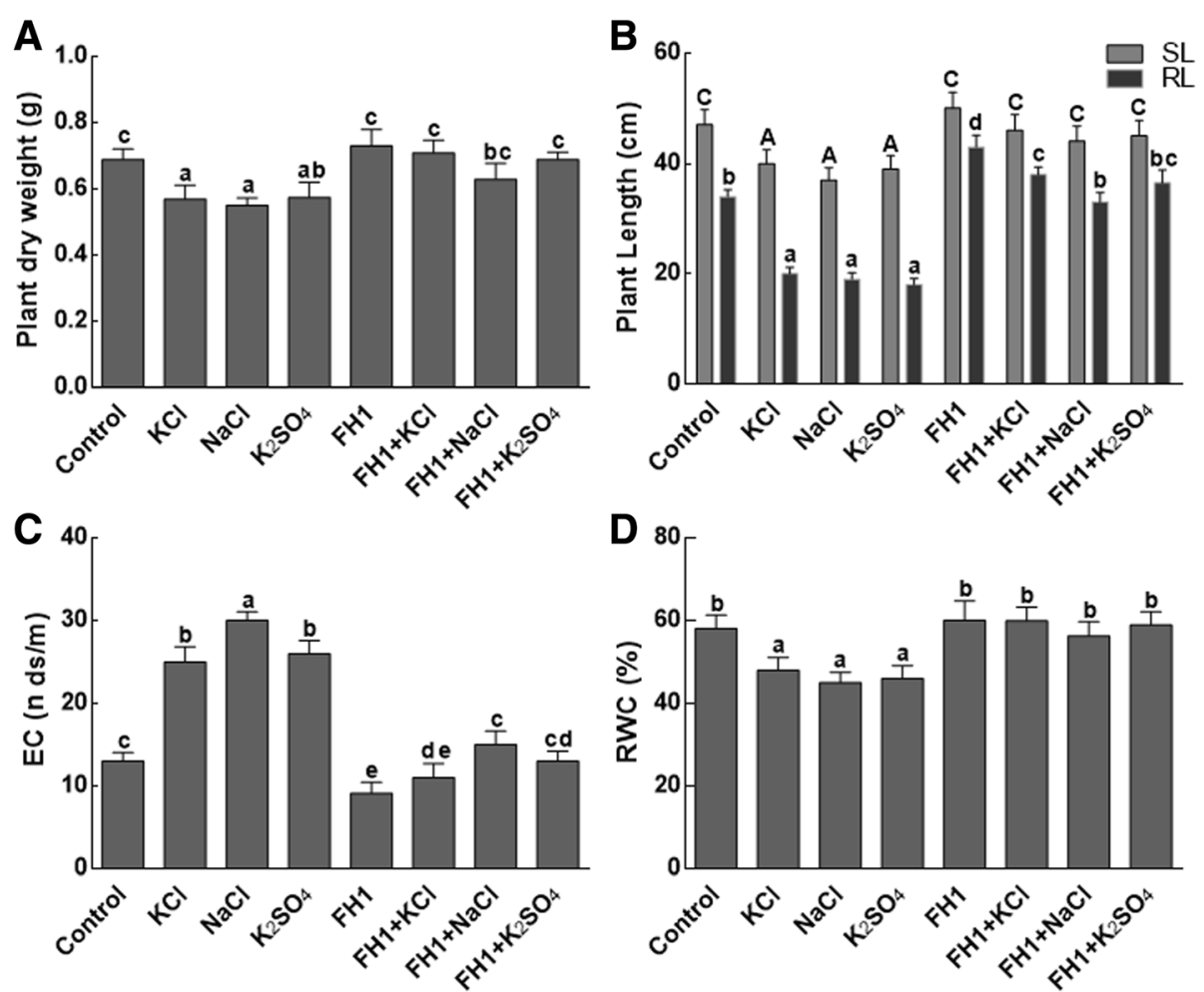

Fig. 3 Effect of different salts on physiochemical characteristics of maize plants. a represents maize plant weights on dry and wet basis; $\mathbf{b}$ represents root and shoot lengths of maize plants under salt stress; $\mathbf{c}$ represents electrolytic leakage of maize plants under salt stress; $\mathbf{d}$ represents relative water content of maize plants under salt stress; $\mathrm{DW}=$ dry weight; $\mathrm{SL}=$ shoot length; $\mathrm{RL}=$ root length; $\mathrm{EC}=$ electrical conductivity; $\mathrm{RWC}=$ relative water content; $\mathrm{FH} 1$ = fungal endophyte; $\mathrm{KCl}=$ potassium chloride; $\mathrm{NaCl}=$ sodium chloride; $\mathrm{K}_{2} \mathrm{SO}_{4}=$ potassium sulphate. Each bar represents the mean of triplicated data with \pm SE. Respective bars that are labeled with different letters is significantly different from one another at $p<0.05$

change has been observed in RWC of maize plants inoculated with $\mathrm{FH} 1$ as compared to the control plants (Fig. 3c).

\section{Effect of Y. lipolytica FH1 on maize endogenous IAA and $A B A$ contents}

The concentration of endogenous IAA was determined in endophytes associated and non-associated maize seedlings cultivated under control (no salt) and saline conditions. The results exhibited that the IAA contents of maize plants have increased by almost $100 \%$, when the plants have inoculated with FH1as compared to the non-inoculated plants (Fig. 4a). A 3 fold increase in percent IAA contents has been recorded in FH1 inoculated stressed plants as compared to the salt stressed controls.

On the contrary, significantly $(P<0.05)$ higher amounts of abscisic acid (ABA) have been noticed in non-inoculated maize plants under salt stress as compared to the inoculated plants (Fig. 4b). Also, non-significant differences concerning the ABA contents have been noticed in the non-inoculated control treatments as compared to the inoculated plants under salinity. In short, the FH1 inoculated plants have significantly lower concentrations of $\mathrm{ABA}$ as compared to their respective controls (Fig. 4b).

\section{Effect of Y. lipolytica FH1association on antioxidant enzymes system}

Salt stress triggered much higher accumulation of proline, peroxidase (POD) and catalase as compared to the non-stressed plants (Fig. 5). However, the fungal inoculation of maize plants under salt stress has significantly $(P<0.05)$ controlled the production of proline, peroxidase (POD) and catalase. Approximately, 3-fold decrease in proline contents (Fig. 5a), 1.5-fold decrease in POD activity (Fig. 5b) and 5-fold decrease in CAT activity (Fig. 5c) have been noted in fungal inoculated maize plant as compared to non-inoculated plants.

\section{Discussion}

Endophytic fungi depend on host plants for nourishment, water and physical protection against biotic and abiotic adversities. In return, the endophyte secretes secondary metabolites, e.g. phenols and flavonoids [12]. A wide array of biologically active secondary metabolites has been isolated from endophytic fungi $[13,14]$. Nonetheless, very little knowledge is available regarding the synthesis and secretion of plant growth regulators, phenols, flavonoids, DPPH activity of the endophytic fungi culture filtrate under salt stress. In this study, we 

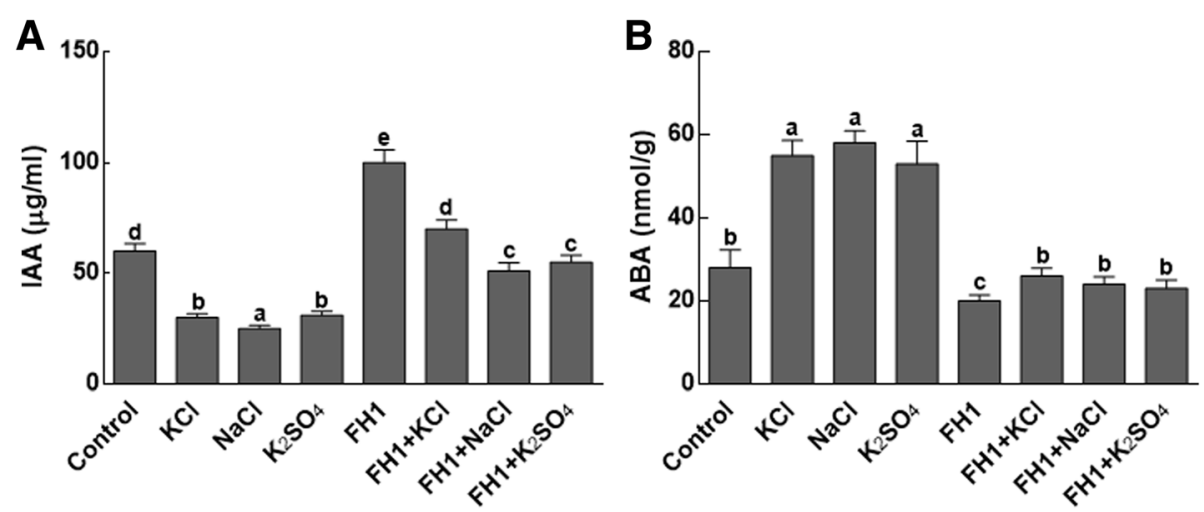

Fig. 4 Quantitative changes in IAA and ABA contents of maize under salt stress. a represents IAA contents of maize plant under salt stress; $\mathbf{b}$ represents $A B A$ contents of maize plants under salt stress; $I A A=$ indole acetic acid; $A B A=$ abscisic acid; $F H 1=$ fungal endophyte; $K C l=$ potassium chloride; $\mathrm{NaCl}=$ sodium chloride; $\mathrm{K}_{2} \mathrm{SO}_{4}=$ potassium sulphate. Each bar represents the mean of triplicated data with $\pm \mathrm{SE}$. Bars that are labeled with different letters are significantly different from one another at $p<0.05$

isolated 9 endophytic fungi from the spines of E. milli, a well-known xerophyte. Y. lipolytica FH1 was selected for current study based on its resistance to $100 \mathrm{mM}$ salt stress and IAA biosynthesis capabilities. The CF of $Y$. lipolytica FH1 was screened for secondary metabolites. Y. lipolytica FH1 produced IAA and promoted growth of maize seedlings. Therefore, restoration of growth in treated maize seedlings might be attributed to the IAA secreted by FH1. The ability of endophytes to produce IAA can be linked with two important putative genes (IaaM and IaaH). The putative IaaM and IaaH genes code for enzymes tryptophan-2-monooxygenase and indole-3-acetamide hydrolase suggested that IAA biosynthesis was a two-step process that progresses via an indole-3-acetamide pathway [15]. Waqas et al. (2012) reported the detection of IAA in the culture filtrates of endophytic isolates of $P$. glomerata and the positive role of IAA in plant growth promotion under saline conditions. Our current findings regarding IAA production and mitigation of salt stress by $Y$. lipolytica $\mathrm{FH} 1$ are in close agreement with that of N Saeed, MR Khan and M Shabbir [16].

On the other hand, various reasons are responsible for the decrease in crop growth under salinity. One of the important reasons may be the limitation of photosynthesis in plants exposed to saline conditions. Under salinity stress chloroplast accumulates excessive $\mathrm{Na}^{+}$, which inhibits PS-II activity and thus deters photosynthesis and ultimately growth rate [17]. Also high salinity induces ethylene production in plants, which inhibit chlorophyll biosynthetic pathway [18]. High amount of $\mathrm{Na}^{+}$in the maize cell might hinder the growth and development of maize through negative osmotic potential, thereby reducing the uptake of water and minerals like $\mathrm{K}^{+}$under salinity stress. The response of maize seedlings to selected salts $\left(\mathrm{KCl}, \mathrm{NaCl}\right.$ and $\left.\mathrm{K}_{2} \mathrm{SO}_{4}\right)$ in the
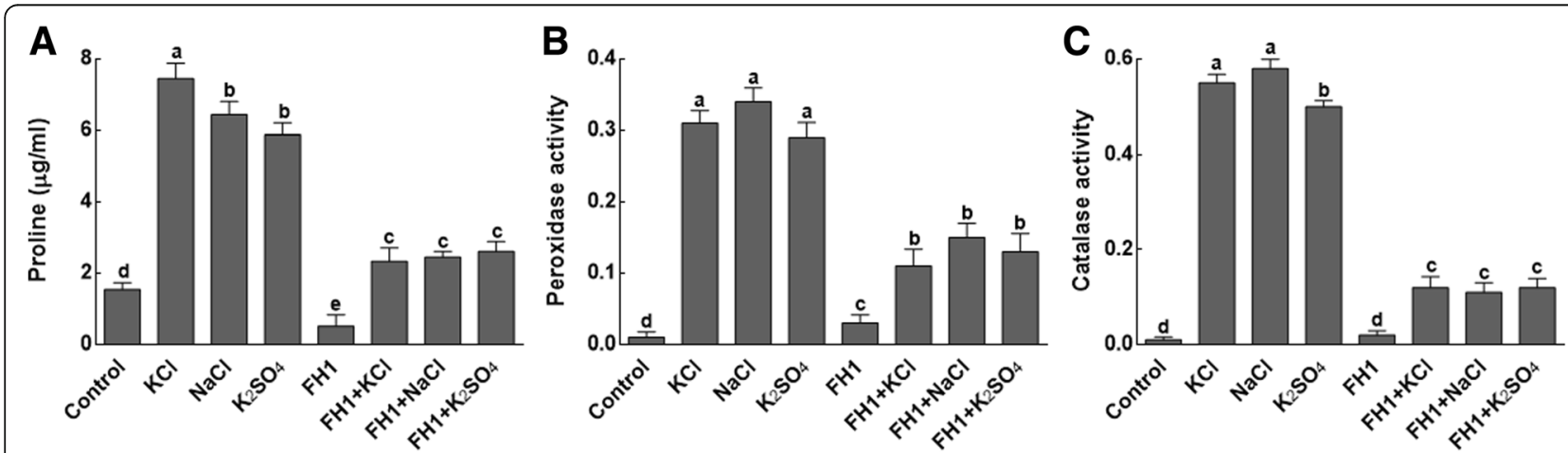

Fig. 5 Effect of different salts sources on oxidizing capacity of maize plants. a represents phenolic contents of maize plants under salt stress; b represents peroxide activity of maize plants under salt stress; $\mathbf{c}$ represents catalase activity of maize plants under salt stress; $\mathrm{FH} 1=$ fungal endophyte; $\mathrm{KCl}$ = potassium chloride; $\mathrm{NaCl}$ = sodium chloride; $\mathrm{K}_{2} \mathrm{SO}_{4}=$ potassium sulphate. Each bar represents the mean of triplicated data with \pm SE. Bars that are labeled with different letters are significantly different from one another at $p<0.05$ 
current study was different. Among the selected salts, $\mathrm{NaCl}$ was the most toxic that limited the growth of maize by interfering with the physiological processes of the maize. The adverse effects of $\mathrm{NaCl}$ were evident from low chlorophyll contents, reduced shoot and root growth, lighter plant (fresh and dry weight basis), low relative water contents and higher electrolytes leakage. The decrease in plant relative water content reflects on physiological drought forcibly imposed on plants, as soil solution in saline areas is hypertonic in relation to cell sap [8].

Another phenomenon that was affected by salt stress was changes in endogenous phytohormones, i.e. high $\mathrm{ABA}$ and low IAA content. ABA is reported to perform key role in the regulation of signaling pathways, which are involved in plant growth and development under salt stress [19]. It has previously been demonstrated that fungal inoculation has a role in increasing ABA contents of host plant under salt stress [13]. Similarly, IAA is essential for plants growth and development due to its function in root, axillary bud and flower development. Certainly, IAA (either exogenous or endogenous) can regulate various developmental processes in plants under abiotic stress $[20,21]$. In this study, high contents of IAA were noticed in plants that were inoculated with Y. lipolytica FH1 and exposed to salt stress. Our results suggested that ABA and IAA have contrasting roles in plant response to salt stress.

Additionally, the inoculated $Y$. lipolytica FH1 helped the maize seedlings to stand against salt stress that was quite evident from the accumulation of pigments (chlorophyll and carotenoids content), a decrease in electrolyte leakage, increased seedlings growth and improvement in leaf relative water content. Indeed, maize seedlings tried to withstand the adverse effects of salts by increasing production of the POD, catalase, and proline. The results suggested that under stress conditions, endophytic fungi modulated the host plant system in order to detoxify the hazardous ROS rather enabling the host plant to avoid uptake of salts. Scavenging of the salt-induced $\mathrm{H}_{2} \mathrm{O}_{2}$ by catalase and peroxidase may be an effective mechanism of plants to overcome salinity stress [22]. Significant aggregation of proline in Paecilomyces formosus associated plants growing under salinity stress, suggesting a decline in ionic influx inside the cellular masses and rescuing plants to maintain its osmotic balance [16]. Besides, the up-regulation of genes associated with CAT, POD and proline in maize plants, the endophyte might also contribute towards the resistance against salinity stress [23] which supports our results.

\section{Conclusion}

From the current findings, we have concluded that the endophytic association of $Y$. lipolytica FH1 with maize plants has significantly improved the growth of maize under salt stress. The recovery of fungal inoculated maize plants (in terms of growth and development) under stress conditions can be linked with the secreation of exogenous IAA and regulation of maize endogenous IAA and ABA. In fact, the normal secretion of endogenous IAA and ABA by maize plants under salinity can be attributed to the association of $Y$. lipolytica FH1. Also, FH1association has controlled the production of POD, CAT and proline in maize plants under salt stress.

\section{Methods}

\section{Isolation of endophytic Fungi}

In the present study, 9 endophytic fungal isolates were isolated from the spines of Euphorbia milli, an ornamental plant easily available at Abdul Wali Khan University, district Mardan. The district lies from $34^{\circ} 05^{\prime}$ to $34^{\circ} 32^{\prime}$ north latitudes and $71^{\prime \prime} 48^{\prime}$ to $72^{\circ} 25^{\prime}$ east longitudes. The average temperature of Mardan is $23.2^{\circ} \mathrm{C}$ with an average rain fall of $110 \mathrm{~mm}$. The characteristics of the soil ranges from sandy loam to clay with $\mathrm{pH}$ from 5.9 to 8.1.

Initially, the spines from the collected plants were cut and washed with tap water. Surface sterilization was carried with $70 \%$ ethanol for $1 \mathrm{~min}$. The sterilized spines were then washed with double distilled water $\left(\mathrm{ddH}_{2} \mathrm{O}\right)$ to remove traces of ethanol. To isolate endophytic fungi, the spines were cut into $0.5 \mathrm{~cm}$ segments and placed carefully in Petri-plates containing Hagem growth media under conditions mentioned above. To confirm the effectiveness of $70 \%$ ethanol, the spines were cut into segments and were surface sterilized. The sterilized pieces of spines were then placed on Hagem media [24] and processed as mentioned earlier. The fungal isolates collected from the Hagem media were grown on PDA media [25].

Endophytic fungi were isolated on Hagem media plates incubated at $28^{\circ} \mathrm{C}$ for 7 days. Subculturing of the endophytic fungal isolates was performed by growing the isolates on PDA plates incubated at $28^{\circ} \mathrm{C}$ for 7 days. For secondary metabolites production, the isolated endophytes were grown in Czapek broth (Peptone 1\%, Glucose, $1,0.05 \% \mathrm{MgSO}_{4 .} 7 \mathrm{H}_{2} \mathrm{SO}_{4}, 0.05 \% \mathrm{KCl}$ and $0.001 \%$ $\left.\mathrm{FeSO}_{4 .} 7 \mathrm{H}_{2} \mathrm{SO}_{4} \quad \mathrm{pH} 7.3 \pm 0.2\right)$ maintained at $28^{\circ} \mathrm{C}$ and $120 \mathrm{rpm}$ for 7 days [26]. After incubation, fungal cultures were filtered to obtain fungal biomass and respective culture filtrate $(\mathrm{CF})$.

\section{Colonization frequency}

Colonization was measured as colonization frequency by plating spine segments on Hagem media plates at $28^{\circ} \mathrm{C}$ for 7 days and counted the number of segments with 
FH1colonies. The colonization frequency of FH1was then calculated as following:

$$
\% \text { Colonization frequency }=\frac{\text { Total twig section colonized }}{\text { Total number of segments colonized }} \times 100
$$

\section{Salt stress tolerance}

Fungal isolate was taken from PDA plates and inoculated in $50 \mathrm{ml}$ Czapek-broth supplemented with $100 \mathrm{mM}$ $\mathrm{NaCl}$ to check its ability to resist salt stress. The cultures in the flasks were then incubated for 7 days at $28^{\circ} \mathrm{C}$ and at $120 \mathrm{rpm}$. After 7 days of incubation, the growth of the inoculated fungal isolates was observed. The endophyte FH1 was selected for further study based on its ability to resist $100 \mathrm{mM} \mathrm{NaCl}$.

\section{Determination of IAA in culture filtrates of FH1 through GC/MS}

Fungal culture filtrate obtained as described earlier were subjected to gas chromatography-mass spectroscopy (GC/MS-SIM) coupled with selected ion monitoring [27]. The CF of isolate was taken in test tubes and filtered through $0.45 \mu \mathrm{m}$ cellulose acetate filters. The $\mathrm{pH}$ of filtrate was adjusted to 3.0 with $1 \mathrm{~N} \mathrm{HCl}$ and then extracted with ethyl acetate. The organic layer was evaporated at $45^{\circ} \mathrm{C}$ in a water bath. The dried sample was then dissolved in $5 \mathrm{ml}$ of $0.1 \mathrm{M}$ acetic acid and eluted through the reverse phase C18 column using 30, 50, $100 \%$ methanol. Methanol from the eluted samples was evaporated at $45^{\circ} \mathrm{C}$ using a water bath. The residues left were dissolved in $1 \mathrm{ml}$ of methanol and added $1.5 \mathrm{ml}$ of ethereal diazomethane to prepare methyl ester fraction. The methylated samples were re-dissolved in ethyl acetate before being analyzed by GC/MS-SIM (6890 N network GC system, and 5973 network mass selective detector; Agilent, Palo Alto, CA, USA). For IAA, $1 \mu \mathrm{L}$ of the sample was injected in a $30 \mathrm{~m} \times 0.25 \mathrm{~mm}$ i.d., $0.25 \mu \mathrm{m}$ film thickness DB-1 capillary column (J \& W Scientific Co., Folsom, CA, USA), respectively. The GC oven temperature was programmed as: holding temperature of $70{ }^{\circ} \mathrm{C}$ for $2 \mathrm{~min}$, then rise to $200{ }^{\circ} \mathrm{C}$ (with a steady increase in temperature, i.e. $20^{\circ} \mathrm{C} /$ minutes) and finally reached to $285^{\circ} \mathrm{C}$ (with an increase of $5{ }^{\circ} \mathrm{C} / \mathrm{mi}$ nutes). Helium as a carrier gas was maintained at a head pressure of $30 \mathrm{kPa}$. The GC was directly interfaced to a mass selective detector with an interface and source temperature of $230{ }^{\circ} \mathrm{C}$, an ionizing voltage of $70 \mathrm{eV}$, and a dwell time of $100 \mathrm{~min}$.

\section{Total phenolics determination}

The total phenolics were determined in the CF of isolate FH1 following the method proposed by A Qawasmeh, HK Obied, A Raman and W Wheatley [28]. A blue coloration indicates the presence of phenol and their absorbance was checked at $650 \mathrm{~nm}$ using SHIMADZU spectrophotometer (Kyoto, Japan). Gallic acid was used as a standard to quantify the total phenol in CF of FH1.

\section{Total flavonoids determination}

Colorimetric determination of flavonoids was carried out in the CF of isolate FH1, following the protocol of K Srinivasan, L Jagadish, R Shenbhagaraman and J Muthumary [29]. Quercitin was used as a standard for flavonoids determination. A white milky coloration indicates the presence of flavonoids.

\section{2, 2 Diphenyl-1-Picrylhydrazyl (DPPH) \% activity}

The CF obtained from our isolate FH1 grown in Czapek medium was assayed for scavenging of the reactive oxygen species (ROS) according to Liu et al., (2007). Approximately, $2 \mathrm{~mL}$ of distilled water, $1 \mathrm{~mL}$ of $0.1 \mathrm{mM} \mathrm{2,2}$ Diphenyl-1-picrylhydrazyl (DPPH) was added to $0.5 \mathrm{~mL}$ of CF from isolate FH1. The mixture was shaken vigorously and allowed to stand for $30 \mathrm{~min}$ at room temperature. The antioxidant activity of CF was determined by measuring the decrease in absorbance at 517 $\mathrm{nm}$ against blank. Methanol was used as a blank and ascorbic acid was used as positive control.

\section{Fungal identification and phylogenetic analysis}

A molecular approach was adopted to identify the selected fungal isolate FH1. The genomic DNA of isolate FH1 was extracted following the established protocol [30] which was previously modified [31]. The fungal isolate FH1 was identified by sequencing the internal transcribed spacer (ITS) region of $18 \mathrm{~S}$ rDNA using universal primers ITS-1 and ITS-4 [32]. The sequence obtained was subjected to BLASTn1 for sequence homology estimation. The evolutionary history of sequences obtained as a result of homology search was inferred by using the Maximum Likelihood method based on the Tamura-Nei model [33]. The analysis involved 25 nucleotide sequences and the evolutionary analyses were conducted in MEGA7 [34]. The gene sequence of the isolate FH1 was submitted to NCBI GenBank and was allotted with accession no. KY673731.

\section{Plant growth promotion and salt stress alleviation potential of $\mathrm{FH} 1$}

Healthy and uniform seeds (30 seeds) of Zea mays L. were surface sterilized by dipping them in $0.1 \% \mathrm{HgCl}_{2}$ followed by washing with double distilled water. Seeds were then allowed to germinate in Petri plates on wet filter papers at $26 \pm 1{ }^{\circ} \mathrm{C}$ in order to get equally germinated seedlings. After germination, seedlings were transferred to pots (pot size width $9 \mathrm{~cm} /$ length $11.3 \mathrm{~cm}$ ) containing autoclaved soil (texture = clay loam; $\mathrm{pH}=7.21 ; \mathrm{EC}=2.1$ ) and the seedlings were allowed to grow and establish in 
soil (for 2-days) before fungal biomass was added to the soil. Soil inoculation was performed by drench inoculation method that involved the application of fresh biomass of selected fungal strain FH1 $(0.3 \mathrm{~g} / 300 \mathrm{~g}$ soil $)$ around the root zone in order to assess their ability of alleviating salinity stress in maize [35]. Salinity stress of $25 \mathrm{ml}$ of water containing $100 \mathrm{mM} \mathrm{NaCl}$ or $\mathrm{KCl}$ or $\mathrm{K}_{2} \mathrm{SO}_{4}$ was applied after every three days for 20 days. The pots have no pores to allow leakage of water and salts. The plants were watered daily. The experiment was terminated after completion of salt stress and plant growth attributes were analyzed, following the established protocol [36]. The plant dry biomass was measured after drying the plants at $70^{\circ} \mathrm{C}$ for $48 \mathrm{~h}$ in an oven

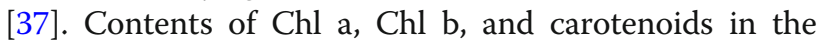
extract of fully expanded maize leaves before harvest was determined using MacKinney equations [38]. Fully expanded fresh leaves of fungal inoculated and non-inoculated maize plants under salt stress were homogenized with $2 \mathrm{ml}$ of acetone $(80 \%)$ and washed twice to reach final volume of $7 \mathrm{ml}$. The absorbance was measured using a spectrophotometer at $480 \mathrm{~nm}, 645 \mathrm{~nm}$, and $663 \mathrm{~nm}$. Electrolyte leakage was determined by adopting standard method [39]. Leaf relative water contents (\%) was measured by following the standard protocol [40]. For the determination of POD, CAT, proline, IAA and ABA, maize seedlings were cut into pieces and frozen immediately in liquid nitrogen and stored in freezer at $-70{ }^{\circ} \mathrm{C}$. The pot experiment was done in triplicate with an experimental outline as follows:

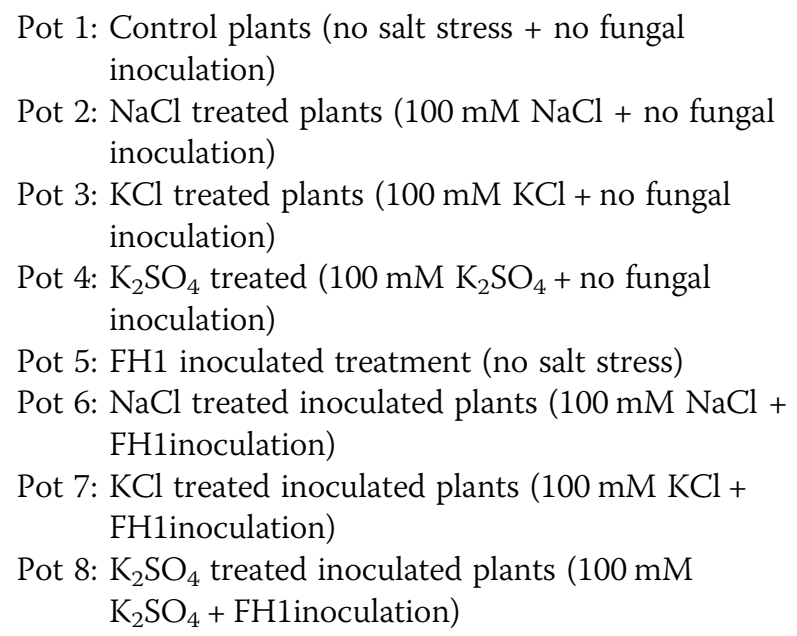

\section{Quantification of maize plant endogenous IAA and ABA}

Plant hormones extraction and purification were analyzed by using HPLC according to the method of Kettner and Döerffling [41]. Fresh plant leaves $(1 \mathrm{~g})$ were ground at $4{ }^{\circ} \mathrm{C}$ in $80 \%$ methanol with butylated hydroxy toluene (BHT) as an antioxidant. After $72 \mathrm{~h}$ extraction, the pooled extract was centrifuged at $3000 \mathrm{rpm}$ and the supernatant was partitioned at $\mathrm{pH} 2.5-3$ with ethylacetate (1/4th volume of the extract). The ethyl acetate phase was dried down completely on the rotary thin film evaporator (RFE) and the residues were re-dissolved in 100\% methanol. The samples were then passed through a Millipore filter $(0.45 \mathrm{u})$ and were analyzed by HPLC (Agilent 1100$)$, equipped with variable UV detector and C18 column $(39 \times 300 \mathrm{~mm})$ (BondaPack Porasil C18, 37/50 $\mu \mathrm{m}$, Waters, Eschborn, BRD). Methanol and water in the ratio of $(30: 70 ; v / v)$ were used as mobile phase at a flow rate of $1500 \mu \mathrm{L} / \mathrm{min}$ and a run time of $20 \mathrm{~min} / \mathrm{sample}$. The plant hormones were identified on the basis of retention time of phytohormone standards.

\section{Determination of catalase activity}

Catalase activity was assayed by previously described method [42]. The activity was estimated by a decrease in the absorbance of $\mathrm{H}_{2} \mathrm{O}_{2}$ at $240 \mathrm{~nm}$ ( $1 \mathrm{U}$ of catalase was defined as conversion of $1 \mu$ mole of $\mathrm{H}_{2} \mathrm{O}_{2}$ per minute).

\section{Estimation of peroxidase activity}

Peroxidase activity (POD) was assayed by following established protocol [43]. Added, $5.55 \mathrm{~g}$ of $\mathrm{CaCl}_{2}$ to 100 $\mathrm{ml}$ of distilled $\mathrm{H}_{2} \mathrm{O}_{2}$ and the resultant solution was cooled on ice prior to use in the assay. After cooling, mixed, $0.5 \mathrm{ml}$ p-Phenylenediamine, $1.5 \mathrm{ml} \mathrm{MES,} 0.1 \mathrm{ml}$ plant extract, and $0.45 \mathrm{ml} \mathrm{H}_{2} \mathrm{O}_{2}$. The MES Buffer alone was used as blank and the optical density was measured at $510 \mathrm{~nm}$, initially soon after mixing the contents and then after 3 min of incubation at room temperature.

\section{Proline contents}

The proline contents of maize seedling was measured according to the method described by JJ Shaw, DJ Spakowicz, RS Dalal, JH Davis, NA Lehr, BF Dunican, EA Orellana, A Narváez-Trujillo and SA Strobel [44]. The fresh leaf samples $(0.2 \mathrm{~g})$ were homogenized in $5 \mathrm{ml}$ (3\%) of aqueous sulphosalicylic acid and the homogenate was subjected to centrifugation at $12,000 \mathrm{rpm}$ for $10 \mathrm{~min}$. Equal volume of glacial acetic acid ninhydrin was then added to the supernatant. The mixture was boiled on a water bath adjusted at $100^{\circ} \mathrm{C}$ for $1 \mathrm{~h}$ and then extraction was done with $4 \mathrm{ml}$ of toluene. The absorbance was measured at $520 \mathrm{~nm}$ using toluene as a blank.

\section{Statistical analysis}

Data analysis was done using SPSS 20 for Windows. Means comparison was done by analysis of variance (ANOVA) and Duncan multiple range test at $P=0.05$.

\section{Abbreviations}

ABA: Abscise acid; CAT: Catalases; CF: Culture filtrate; DNA: Deoxyribo nucleic acid; DPPH: Diphenyl-1-Picrylhydrazyl; GC: Gas chromatography; GC/MS- 
SIM: Gas chromatography/mass spectroscopy- selected ion monitoring; HPLC: High performance liquid chromatography; IAA: Indole-3-acetic acid; POD: Peroxidases

\section{Acknowledgements}

The authors are thankful to the lab members of Abdul Wali Khan Univrsity Mardan and Kyungpook University Korea for technical support.

\section{Funding}

This research was supported by the Basic Science Research Program through the National Research Foundation of Korea (NRF) funded by the Ministry of Education (2017R1D1A1B04035601). The funding body just provided the funds and doesn't have any practical role in the design of the study and collection, analysis, and interpretation of data and in writing the manuscript.

\section{Availability of data and materials}

The datasets generated and analyzed during this study are available from the corresponding author upon reasonable request.

\section{Authors' contributions}

$\mathrm{MH}$ and IJL designed the experiments, supervised the study, provided the lab resources, involved in acquisition of data and finalized the manuscript. FGJ and GJ performed all the experiments, collected the data and along with $\mathrm{AH}$ and $\mathrm{Al}$ wrote the draft manuscript. $\mathrm{AH}, \mathrm{Al}$ and $\mathrm{AK}$ analysed the data. $\mathrm{AH}, \mathrm{MH}, \mathrm{Al}$ and IJL critically revised the manuscript. FGJ, GJ, $\mathrm{MH}, \mathrm{AH}, \mathrm{GJ}, \mathrm{Al}$, $A K$ and IJL read, discussed and significantly improved the manuscript before approving the final draft. All authors read and approved the final manuscript

\section{Ethics approval and consent to participate}

The research doesn't involve and endangered plant species and doesn't require any approval.

\section{Consent for publication}

Not Applicable

\section{Competing interests}

The authors declare that they have no competing interests.

\section{Publisher's Note}

Springer Nature remains neutral with regard to jurisdictional claims in published maps and institutional affiliations.

\section{Author details \\ 'Department of Botany, Garden Campus, Abdul Wali Khan University Mardan, Mardan, Pakistan. ${ }^{2}$ Department of Agriculture, Garden Campus, Wali Khan University Mardan, Mardan, Pakistan. ${ }^{3}$ Ministry of Education, Key Laboratory of Cell Activities and Stress Adaptations, School of Life Science, Lanzhou University China, Lanzhou, China. ${ }^{4}$ School of Applied Biosciences, College of Agriculture and Life Sciences, Kyungpook National University, Daegu, South Korea.}

Received: 7 December 2017 Accepted: 11 December 2018

Published online: 07 January 2019

\section{References}

1. McWilliam J. The national and international importance of drought and salinity effects on agricultural production. Funct Plant Biol. 1986;13(1):1-13.

2. Eker S, Cömertpay G, Konuşkan Ö, Ülger AC, Öztürk L, Çakmak I. Effect of salinity stress on dry matter production and ion accumulation in hybrid maize varieties. Turk J Agric For. 2006;30(5):365-73.

3. Qadir M, Noble AD, Karajeh F, George B. Potential business opportunities from saline water and salt-affected land resources, vol. 5: International Water Management Institute (IWMI). Colombo: CGIAR Research Program on Water, Land and Ecosystems (WLE); 2015. https://doi.org/10.5337/2015.206.

4. Debez A, Saadaoui D, Slama I, Huchzermeyer B, Abdelly C. Responses of Batis maritima plants challenged with up to two-fold seawater $\mathrm{NaCl}$ salinity. J Plant Nutr Soil Sci/Z Pflanzenernähr Bodenkd. 2010;173(2):291.

5. Munns R. Comparative physiology of salt and water stress. Plant Cell Environ. 2002;25(2):239-50
6. Munns R, James RA, Sirault XR, Furbank RT, Jones HG. New phenotyping methods for screening wheat and barley for beneficial responses to wate deficit. J Exp Bot. 2010;61(13):3499-507.

7. Xiong L, Schumaker KS, Zhu J-K. Cell signaling during cold, drought, and salt stress. The plant cell. 2002;14(suppl 1):S165-83.

8. Hardoim PR, van Overbeek LS, van Elsas JD. Properties of bacterial endophytes and their proposed role in plant growth. Trends Microbiol. 2008;16(10):463-71.

9. Apel K, Hirt H: Reactive oxygen species: metabolism, oxidative stress, and signal transduction. Annual Review of Plant Biology 2004, 55:373-399. 310. 1071/FP04232

10. Fecht-Christoffers MM, Führs H, Braun H-P, Horst WJ. The role of hydrogen peroxide-producing and hydrogen peroxide-consuming peroxidases in the leaf apoplast of cowpea in manganese tolerance. Plant Physiol. 2006;140(4): 1451-63.

11. Prusty R, Grisafi P, Fink GR. The plant hormone indoleacetic acid induces invasive growth in Saccharomyces cerevisiae. Proc Natl Acad Sci. 2004;101(12):4153-7.

12. Pan F, Su T-J, Cai S-M, Wu W. Fungal endophyte-derived Fritillaria unibracteata var. wabuensis: diversity, antioxidant capacities in vitro and relations to phenolic, flavonoid or saponin compounds. Sci Rep. 2017;7:42008.

13. Hamayun M, Hussain A, Khan SA, Kim H-Y, Khan AL, Waqas M, Irshad M, labal A, Rehman G, Jan S. Gibberellins producing endophytic fungus Porostereum spadiceum AGH786 rescues growth of salt affected soybean. Front Microbiol. 2017:8:686

14. Bilal L, Asaf S, Hamayun M, Gul H, lqbal A, Ullah I, Lee I-J, Hussain A. Plant growth promoting endophytic fungi Asprgillus fumigatus TS1 and Fusarium proliferatum BRL1 produce gibberellins and regulates plant endogenous hormones. Symbiosis. 2018;76:117-27.

15. Lehmann $T$, Hoffmann M, Hentrich M, Pollmann S. Indole-3-acetamidedependent auxin biosynthesis: a widely distributed way of indole-3-acetic acid production? Eur J Cell Biol. 2010;89(12):895-905.

16. Saeed N, Khan MR, Shabbir M. Antioxidant activity, total phenolic and total flavonoid contents of whole plant extracts Torilis leptophylla L. BMC Complement Altern Med. 2012;12(1):221.

17. Ali A, Basra SM, lqbal J, Hussain S, Subhani M, Sarwar M, Haji A. Silicon mediated biochemical changes in wheat under salinized and non-salinzed solution cultures. Afr J Biotechnol. 2012;11(3):606-15.

18. Fahad S, Hussain S, Matloob A, Khan FA, Khaliq A, Saud S, Hassan S, Shan D, Khan F, Ullah N. Phytohormones and plant responses to salinity stress: a review. Plant Growth Regul. 2015;75(2):391-404.

19. Van Ha C, Leyva-González MA, Osakabe Y, Tran UT, Nishiyama R, Watanabe Y, Tanaka M, Seki M, Yamaguchi S, Van Dong N. Positive regulatory role of strigolactone in plant responses to drought and salt stress. Proc Natl Acad Sci. 2014;111(2):851-6.

20. Verma $\vee$, Ravindran P, Kumar PP. Plant hormone-mediated regulation of stress responses. BMC Plant Biol. 2016;16(1):86.

21. Glick BR. Plant growth-promoting bacteria: mechanisms and applications. Scientifica. 2012;2012:1-15. https://doi.org/10.6064/2012/963401.

22. Sofo A, Scopa A, Nuzzaci M, Vitti A. Ascorbate peroxidase and catalase activities and their genetic regulation in plants subjected to drought and salinity stresses. Int J Mol Sci. 2015;16(6):13561-78.

23. Badawi GH, Yamauchi Y, Shimada E, Sasaki R, Kawano N, Tanaka K, Tanaka K. Enhanced tolerance to salt stress and water deficit by overexpressing superoxide dismutase in tobacco (Nicotiana tabacum) chloroplasts. Plant Sci. 2004;166(4):919-28.

24. Redman RS, Kim YO, Woodward CJ, Greer C, Espino L, Doty SL, Rodriguez RJ. Increased fitness of rice plants to abiotic stress via habitat adapted symbiosis: a strategy for mitigating impacts of climate change. PLoS One. 2011;6(7):e14823.

25. Jumpponen A, Trappe JM. Dark septate endophytes: a review of facultative biotrophic root-colonizing fungi. New Phytol. 1998;140(2):295-310.

26. Khan KN, Kitajima M, Imamura T, Hiraki K, Fujishita A, Sekine I, Ishimaru T, Masuzaki H: year=2008. 2008

27. Mohite B. Isolation and characterization of indole acetic acid (IAA) producing bacteria from rhizospheric soil and its effect on plant growth. $J$ Soil Sci Plant Nutr. 2013:13(3):638-49.

28. Qawasmeh A, Obied HK, Raman A, Wheatley W. Influence of fungal endophyte infection on phenolic content and antioxidant activity in grasses: interaction between Lolium perenne and different strains of Neotyphodium lolii. J Agric Food Chem. 2012;60(13):3381-8.

29. Srinivasan K, Jagadish L, Shenbhagaraman R, Muthumary J. Antioxidant activity of endophytic fungus Phyllosticta sp. isolated from Guazuma tomentosa. J Phytol. 2010;2(6):37-41. 
30. Płaza G, Upchurch R, Brigmon R, Whitman W, Ulfig K. Rapid DNA extraction for screening soil filamentous fungi using PCR amplification. Polish Journal of Environmental Studies. 2004;13(3):315-8 doi: 310.15244. Kraj, PL.

31. Gul F, Hussain A, Jan G, Hamayun M. Genomic DNA extraction for molecular identification of endophytic Fungi: an easy and efficient protocol. Biosciences Biotechnology Research Asia. 2017;14(2):667-71.

32. Gardes M, Bruns TD. ITS primers with enhanced specificity for basidiomycetes-application to the identification of mycorrhizae and rusts. Mol Ecol. 1993;2(2):113-8.

33. Tamura K, Nei M. Estimation of the number of nucleotide substitutions in the control region of mitochondrial DNA in humans and chimpanzees. Mol Biol Evol. 1993;10(3):512-26.

34. Kumar S, Stecher G, Tamura K. MEGA7: molecular evolutionary genetics analysis version 7.0 for bigger datasets. Mol Biol Evol. 2016;33(7):1870-4.

35. Tefera T, Vidal S. Effect of inoculation method and plant growth medium on endophytic colonization of sorghum by the entomopathogenic fungus Beauveria bassiana. BioControl. 2009;54(5):663-9.

36. Sumanta N, Haque Cl, Nishika J, Suprakash R. Spectrophotometric analysis of chlorophylls and carotenoids from commonly grown fern species by using various extracting solvents. Res J Chem Sci. 2014;2231:606X.

37. Bohm P. Estimating willingness to pay: why and how? Scand J Econ. 1979: 142-53 DOl: 1https://doi.org/10.1111/sjoe.12168.

38. Sestak Z, Catsky J, Jarvis PJ. Determination of chlorophylls a and b. Plant photosynthetic production: Manual of Methods. Praque; 1971. p. 673-701.

39. Lutts S, Kinet J, Bouharmont J. Effects of salt stress on growth, mineral nutrition and proline accumulation in relation to osmotic adjustment in rice (Oryza sativa L.) cultivars differing in salinity resistance. Plant Growth Regul. 1996;19(3):207-18.

40. Xia J, Liu M-Y, Jia S-F. Water security problem in North China: research and perspective. Pedosphere. 2005;15(5):563-75.

41. Kettner J, Dörffling K. Biosynthesis and metabolism of abscisic acid in tomato leaves infected with Botrytis cinerea. Planta. 1995;196(4):627-34.

42. Sherameti I, Shahollari B, Venus Y, Altschmied L, Varma A, Oelmüller R. The endophytic fungus Piriformospora indica stimulates the expression of nitrate reductase and the starch-degrading enzyme glucan-water dikinase in tobacco and Arabidopsis roots through a homeodomain transcription factor that binds to a conserved motif in their promoters. J Biol Chem. 2005, 280(28):26241-7 doi:26210.21074/jbc.M26116.765776.

43. Zhang X, Fan X, Li C, Nan Z. Effects of cadmium stress on seed germination, seedling growth and antioxidative enzymes in Achnatherum inebrians plants infected with a Neotyphodium endophyte. Plant Growth Regul. 2010;60(2):91-7.

44. Shaw JJ, Spakowicz DJ, Dalal RS, Davis JH, Lehr NA, Dunican BF, Orellana EA, Narváez-Trujillo A, Strobel SA. Biosynthesis and genomic analysis of mediumchain hydrocarbon production by the endophytic fungal isolate Nigrograna mackinnonii E5202H. Appl Microbiol Biotechnol. 2015;99(8):3715-28.

Ready to submit your research? Choose BMC and benefit from:

- fast, convenient online submission

- thorough peer review by experienced researchers in your field

- rapid publication on acceptance

- support for research data, including large and complex data types

- gold Open Access which fosters wider collaboration and increased citations

- maximum visibility for your research: over $100 \mathrm{M}$ website views per year

At $\mathrm{BMC}$, research is always in progress.

Learn more biomedcentral.com/submissions 